\title{
The making of Al society: Al futures frames in German political and media discourses
}

\author{
Lea Köstler ${ }^{1} \cdot$ Ringo Ossewaarde $^{1}$ (1)
}

Received: 12 November 2020 / Accepted: 15 February 2021 / Published online: 28 February 2021

(c) The Author(s) 2021

\begin{abstract}
In this article, we shed light on the emergence, diffusion, and use of socio-technological future visions. The artificial intelligence (AI) future vision of the German federal government is examined and juxtaposed with the respective news media coverage of the German media. By means of a content analysis of frames, it is demonstrated how the German government strategically uses its AI future vision to uphold the status quo. The German media largely adapt the government's frames and do not integrate alternative future narratives into the public debate. These findings are substantiated in the framing of AI futures in policy documents of the German government and articles of four different German newspapers. It is shown how the German past is mirrored in the German AI future envisioned by the government, safeguarding the present power constellation that is marked by a close unity of politics and industry. The German media partly expose the government's frames and call for future visions that include fundamentally different political designs less influenced by the power structures of the past and present.
\end{abstract}

Keywords AI $\cdot$ Content analysis $\cdot$ Frames $\cdot$ Futures $\cdot$ German policy and media communication

\section{Introduction}

Artificial intelligence (AI) is widely presented as an emergent technology that is destined to change the rules of society, peoples' behavior and, ultimately, the way people perceive life (cf. Carbonell et al. 2016; Caruso 2018; Horowitz 2018; Makridakis 2017). The political expectations of AI are immense despite the absence of a universal definition of AI, the high level of uncertainty surrounding AI developments, and skepticism concerning the benefits of AI technologies for society (Callaghan 2018; Gansser 2019; Kinkartz 2019; Totschnig 2019). Political-administrative actors, including the United Nations, the European Union, and national governments, have recently drafted their AI strategies (Cath et al. 2017; European Commission 2020; Lauterbach 2019; Ossewaarde and Gülenç 2020; Villani 2018). In such

Ringo Ossewaarde

m.r.r.ossewaarde@utwente.nl

https://www.utwente.nl/en/bms/pa/staff/ossewaarde/

Lea Köstler

lea.koestler@t-online.de

1 Department of Public Administration, University of Twente, Enschede, The Netherlands political documents, political-administrative actors communicate their ideas about, and visions for, the future of AI. This AI future is typically framed in terms of the new "age of AI" or the "AI revolution" (Bourne 2019; Callaghan and Schnell 2001; Wolfe et al. 2013).

Frames-defined as schemata of interpretation that are employed to structure experiences, interpret events, and make sense of ambiguous information (Goffman 1974) play an influential role in conveying political and popular interpretations of ambiguous phenomena and complex political issues such as AI. Frames do not only influence the public understanding and sensemaking processes of emerging technologies: they equally affect the envisioning of futures in which new technologies are expected to be crucial (Cobb 2005; Metze 2018; Ouchchy et al. 2020; Veenman et al. 2019; Williams 2006). Berendt points out that, when it comes to publicly conveying the meaning of AI, "the framing of a problem has a powerful effect on how people [...] perceive the world and act in it" (Berendt 2019, p. 53). As a consequence, examining "the role of the state and other forms of power in creating authoritative discourses is central to understanding how a particular future has become hegemonic" (Inayatullah 2012, p. 44). 
The enforcement of AI futures frames by governments and media is an exercise of hegemony that affects public understanding. Media frequently reveal a biased-typically a positive and benefit-oriented coverage — of emerging technologies (Kohring and Matthes 2002; Donk et al. 2012). Public debates on $\mathrm{AI}$ are frequently dominated by corporate interests; and media tend to uncritically consider AI as a futuristic solution to all kinds of challenges the nation faces (Brennen et al. 2018). Governments, media, and tech firms exercise a certain linguistic hegemony, in the sense that they enact particular (typically misplaced) metaphors and (typically fraudulent) myths (Rip and Voß 2013; Carbonell et al. 2016; Ossewaarde 2019). Such metaphors and myths shape the interpretation of the meaning and significance of AI and AI futures (Floridi 2019; Horowitz 2018; Lauterbach 2019; Ossewaarde and Gülenç 2020). Given that such politics of AI are characterized by the exercise of domination and restriction of the imagination, there is an urgent need for a more sophisticated debate on AI (Ouchchy et al. 2020). This discourse is fundamental to enable the public to build a reasoned opinion on possible AI futures.

In Germany, AI and AI futures have become a widely discussed topic of public discourse in the past few years. It is a discourse that is marked by a certain alarmism about the future of the German economy. Germany has Europe's largest economy. It is an economy that is largely based on traditional industrial sectors (such as automobiles, machinery, electrical equipment, and chemical and pharmaceutical industries). While the German economy is strong in such sectors, it has somewhat missed out on the Digital Revolution, which has been shaped mainly by Silicon Valley tech firms. At the heart of the German public discourse is the message that Germany should rapidly catch up technologically. It is communicated that Germany needs to re-configurate its economy (including its workforce), and become Europe's world leader in AI, as it had been the leader in traditional industrial sectors. This distinctively German vision is primarily communicated to the public by the German government and the German media, which are the two leading actors that shape public opinion about the German future of AI. Both government and media create and enforce frames to explain what AI means and how society is destined to look in AI futures (Carbonell et al. 2016; Caruso 2018; Berendt 2019; Glazier and Boydstun 2012; Kim et al. 2017).

In this article, we seek to critically assess AI futures frames diffused by the German government and the German media. We seek to find out how the German government and the German news media envision and frame the upcoming AI future in Germany. We are interested in how the German government and German media seeks to affect public understanding, interpretation, and acceptance of AI technologies. Policy and media images of AI futures have been an under-researched topic. Considering that "frames tend to be reiterated and 'echoed' and can survive even in the face of clear scientific evidence that contradicts a frame" (Berendt 2019, p. 54), examining dominant frames in political and public debates is essential for shaping more informed and reasoned public opinion on $\mathrm{AI}$ and possible AI futures.

As a first step, we elaborate the theoretical background of AI futures frames that we apply in the analysis. To develop a profound understanding of the dominant AI future visions in German political and media discourse, we perform a content analysis of AI futures frames. In the analysis section, we highlight political power structures underlying AI future visions in Germany and examine to what extent the German media reinforce the German government's AI futures frames. We argue that the German government strategically uses the German industrial past as a mirror of the German AI future to protect its powerful position as Europe's leading economy. We show how the German government closely aligns with the German industry, together promoting the equation of technological development with social progress. Furthermore, we demonstrate that this mirroring of Germany's industrial past in the German AI future is, to a great extent, echoed in German newspaper coverage, especially regarding the German AI economy. However, we find that German newspapers also play a democratizing role. They encourage public debate on the shaping of alternative AI futures, emphasizing that - and AI futures in particular-should be more than mere mirror images of Germany's industrial past. We conclude by discussing the wider implications of our findings for developing an understanding of AI and society as well as for political and media communication on emerging AI technologies.

\section{Al futures frames as mirror of the past}

\subsection{Envisioning Al futures}

AI futures refer to a period of time that is to come-a period in which $\mathrm{AI}$ technologies are expected to play a crucial role, even amounting to a "new" period of time or a "new age", that is, the so-called "age of AI" (Bourne 2019; Horowitz 2018; Makridakis 2017; Wolfe et al. 2013). However, a universal, unambiguous definition of AI does not exist. In this article, we apply a social definition of AI, that is, what policy makers and newspapers generally consider to be AI. Futures in general, and AI futures in particular, can be understood as an open space, an area not yet explored, a room full of possibilities (Callaghan 2018; Inayatullah 2008; Meyer 2019; Sand 2019). Consequently, various visions of AI futures exist simultaneously, and in this article, we use the plural of the term "future" to underline the openness of future AI developments. 
Today, futures are increasingly predetermined by certain technological developments. Technology is expected to deliver welfare and security, which makes it a strategic resource for governments (van Lente and Rip 1998; Williams 2006). Over the last decades, AI has become such a strategic resource that is expected to have a major impact on the future-hence we speak of "AI futures" (Floridi 2019; Horowitz 2018; Makridakis 2017; Metze 2018). To realize AI futures, resources and public support for, and acceptance of, AI need to be mobilized by a variety of actors, including the government and media (Bourne 2019; Gill 2019; Olesen 2014; Rip and Voß 2013). Such mobilization of resources is initiated by a strategic envisioning of AI futures that political-administrative actors typically illustrate in their AI strategies (The Federal Government 2018b; UK Government 2018; Villani 2018). Envisioned futures are marked by stories, ideas, and futuristic visions - typically phrased in memorable ways - that reduce uncertainty and provide orientation in the present (Augustine et al. 2019; Caruso2018; Gill2018; Jasanoff and Kim 2015). They are typically based on hopes and predictions concerning technological developments that are supposed to define the future. Often, envisioned futures are representations of widely shared expectations about futures that may be possible, plausible, probable, and desirable (Meyer 2019).

\subsection{The use of Al futures frames}

Once an envisioned AI future has been constructed, it is transformed from a promise into a requirement, with AI then being defined as indispensable for social welfare and national security (Bourne 2019; Callaghan 2018; Gill 2018). To become widely accepted and viable, AI future visions are promoted and diffused via the use of frames. AI futures frames are schemata of interpretations that are employed to structure AI experiences, interpret AI events (like technological breakthroughs, AI-related scandals, etc.), and make sense of unclear or contradictory information concerning AI (cf. Goffman 1974; van Wijck and Niemeijer 2016; Veenman et al. 2019). In this conception, AI futures frames are organizing principles that determine how complex and uncertain information about AI futures is processed. Consequently, frames play an important role in the sensemaking processes through which social worlds are being constructed and interpreted by individuals. Accordingly, sensemaking activities allow actors to create a collective understanding of AI and the world, which may serve as a foundation for collective action in shaping futures. These activities of sensemaking become particularly impactful if a clear interpretation of the available information is missing (Meyer 2019). Successful future visions typically do not give detailed information about AI but provide more general (and simplified) interpretations (Berendt 2019; Entman 1993; Jasanoff2018). These simplifications mask complexities and ambiguities, and they help the audience to grasp the communicated meaning of an unfolding AI future, including the meaning of AI (Carbonell et al. 2016; Floridi 2019; Meyer 2019; Veenman et al. 2019).

AI futures frames are not only a matter of cognition but also of communication, marked by strategic use of language (Entman 1993). According to Entman, frames in communication have four basic functions: they (1) define problems, (2) diagnose causes, (3) make moral judgements and (4) suggest solutions. In this way, AI futures frames provide a clear and simple interpretation of AI new realities and become effective if they "select[s] what should be seen and divert[s] attention away from other features" (van Hulst and Yanow 2016, p. 96). It is the frame's simplification that makes it possible to rapidly diffuse envisioned AI futures among the audience. These envisioned AI futures can be classified as distant futures, meaning that they are characterized by high levels of uncertainty, focus on imaginable alternative future scenarios, and center around the orientation and mobilization of collective action (Augustine et al. 2019). Via consistent reinforcement in political-administrative and media discourses, AI futures frames are used to shape public perceptions of a new AI reality in the making and become part of public opinion (Berendt 2019; Jasanoff 2018; Metze 2018). This influence on public opinion might ultimately impact the development of AI in the future and how governments regulate emerging AI technologies (Brennen et al. 2018; Ouchchy et al. 2020). Examining dominant AI futures frames employed in public discourse consequently is an appropriate approach to uncover hidden interests and power structures underlying AI futures.

\subsection{Diffusing Al futures frames}

The need for resource mobilization to attain global AI leadership make AI futures frames ultimately a political phenomenon. As only one version of possible futures can become reality, a fight for (discursive) hegemony among them exists (Ossewaarde 2017). Metze points out "that the competition between futurity framing influences public acceptance and the governance of technologies and is able to close down discursive rooms" (Metze 2018, p. 1739). In other words, AI futures frames are confronted with rival futures frames in a quest for discursive hegemony. Hegemonic futures frames contain the power to enact an interpretation that silences alternative futures frames, thereby closing down possible future trajectories. Political-administrative interests are integral to future visions and actors may benefit from envisioned futures in different ways (Glazier and Boydstun 2012; Inayatullah 2012; van den Heijkant and Vliegenthart 2018; van Wijck and Niemeijer 2016). Ligtvoet et al. argue that 
"Although the future is inherently uncertain and ambiguous, it is not empty but rather influenced by thinking and strategies of today" (Ligtvoet et al. 2016, p. 20). Governments promote their envisioned AI future to mobilize support. They use the future strategically to enhance the probability of achieving its policy goals (Bourne 2019; Inayatullah 2008; Meyer 2019; Sand 2019; Veenman et al. 2019). In their privileged position, political elites are often the first to frame futures and they try to amplify their favored frames in the media coverage (Berendt 2019; Haynes et al. 2016; van Wijck and Niemeijer 2016).

Yet, news media corporations may not necessarily adopt political frames of AI. They also construct and apply their own media frames; for instance, to reach a larger readership and increase profits (Beck 2018; Brennen et al. 2018; Cacciatore et al. 2016). Moreover, in a democratic society, media are not only media corporations operating in media markets (Callaghan and Schnell 2001; Magin and Geiß 2019). They not only sell news to an audience of news consumers: they are also democratic actors. In a democratic society, media agencies are expected to question governments'strategies and policies, including the frames they seek to enact (Cobb 2005; Druckman and Bolsen 2011; Wolfe et al. 2013). Consequently, the media's democratic role is to critically assess AI future visions by exposing AI futures frames and to create alternative ideas, opinions, and outlooks. Thus, analyzing AI futures frames in political and media discourse should demonstrate the competition among frames that are introduced into the debate by various powerful actors for different interests.

\subsection{Al futures frames as a mirror of the past}

Over the last decade, various nation states, international organizations and private companies have published strategy papers telling their story of AI futures (Cath et al. 2017; Dafoe 2018; Lauterbach 2019; Ossewaarde and Gülenç 2020). In the construction of their frames, they often use the past as a mirror of the future. Their key narrative is that the future is a more modern version of the past which means that fundamental structures of politics, society, and economy remain. Political authorities project established patterns, current policies, and today's power constellations on the future conveying the impression that their political rule is indefinite, and history has ended (Ossewaarde 2017). In these specific future frames, present political, social, and economic structures are scarcely criticized and often prevail in the envisioned future. In this way, AI futures-planned by and for the established power holders -represent mirror images of the past. Often, there is little political willingness to discern the outlines and opportunities of emergent social and economic systems or to create systems benefitting a different order (Krantz 2012). As expressed by Krantz "the importance of not only looking [...] in the rear-view mirror to achieve understanding but also looking through the windshield" (Krantz 2012, p. 1) is disregarded in the political envisioning of futures. By mirroring the past in the future, alternative future visions are excluded, and past and current assumptions, beliefs, and biases are maintained.

Despite the allegedly disruptive potential of emerging AI technologies in the so-called "age of AI" (Horowitz 2018; Makridakis 2017; Totschnig 2019), new, alternative ways of thinking, ways of seeing the world and organizing society are rarely envisioned. The mirror held up to the public by political authorities provides an unambiguous image of AI futures; however, their visions are strongly marked by the power structures of the past. There is no willingness "to move out of the present to create the possibility of new futures" (Inayatullah 2012, p. 40) which represents more than the extension of the past and today's capitalist world order. In the words of Bourne, governments ably communicate the message that "whichever state can prove its economy and society to be most 'adaptable, networked and future-oriented' will emerge victorious in neoliberalism's latest global game" (Bourne 2019, p. 116).

In conclusion, we argue that the German government and the German media both envision AI futures and communicate these to the public by constructing AI futures frames. These frames mask the ambiguity and openness integral to possible AI futures and are used to orient and mobilize public action. As political and media interests diverge, the AI futures frames that help the public to make sense of new AI realities, also differ. Considering previous research uncovering the strategic use of envisioned, distant futures (Augustine et al. 2019; Inayatullah 2012; Ossewaarde 2017) we expect that the German government outlines a political vision of a German AI future that is marked by the promise of Wirtschaft und Wohlstand via technological development. We expect that, given Germany's industrial past, the German AI future envisioned by the German government is predominately state- and industry-centered, and comes with a colonization of the German future that serves status quo interests. Finally, we expect that German newspapers reinforce political frames in its corporate role and contest such frames in its democratic role.

\section{Methods}

In this article, we seek to identify AI futures frames that are enacted in the German political and media discourse of AI futures. Current German public discourse on AI provides an interesting case about a public discourse in which a nation celebrates its industrial past. However, Germany is acutely aware that it has missed out on the Digital Revolution, and it does not want to miss out on the alleged "AI Revolution". 
The German public discourse on AI conveys the message that Germany-Europe's largest economy-is to become Europe's world leader in AI, just as it had been a world leader in automobiles. In Germany, the federal ministries for Education and Research (BMBF), Economy and Energy (BMWi), and Labour and Social Affairs (BMAS) communicate their visions of an upcoming AI future and their AI strategies for realizing such a future. In German discourses, AI was initially discussed in terms of its possible economic impact on Germany's industry focusing on the future of work and research (BMWi 2015). But as AI turned from an economic into a public issue by increasingly impacting the private lives of citizens (BMBF 2018), the three German ministries worked out their common "Artificial Intelligence Strategy", which was published in November 2018.

To find out whether the German media amplify the government's vision and diffuse the same AI futures frames to the public, we analyze German newspaper coverage. The newspaper coverage of AI futures in Germany is particularly interesting, considering the importance attached to independent journalism and diversity of opinion in Germany in the context of its histories of totalitarian intelligence agencies, propaganda, persecution and Gleichschaltung. In Germany, the freedom of the press is guaranteed by the Basic Law, and state intervention in the press is confined to a discrimination-free media policy (Beck 2018). Yet, recently, civil society groups have criticized "swarm journalism", claiming that German news coverage has become increasingly one-sided (Röper 2016). What makes the German public discourse on AI so illuminating is that, in Germany, the political and media framing of AI futures illustrates the clash between economic interests and traditional values erupting with the prospect of AI futures. As the strongest national economy in Europe, Germany is expected to play a leading role in the upcoming AI economy. However, it is traditionally a manufacturing nation, lagging in the process of digitalization (PwC, 2018). The German data protection standards are exceptionally high, and the public is relatively skeptical of new AI technologies (Gansser 2019). Given this specific background, the German media can be expected to have a strong, democratic position discussing the upsides and downsides of AI futures controversially. Thus, our findings could deviate from previous research stressing the uncritical stance of media outlets on emerging technologies and their impact on society (Bourne 2019; Brennen et al. 2018; Donk et al. 2012; Kohring and Matthes 2002).

Policy papers on AI constitute the basis for our data collection. As decision-making tools, they define policy issues, identify and evaluate policy options, and recommend policy measures (Blümel 2018). Thus, their basic functions overlap with Entman's conceptualization of frames (Entman 1993). By defining relevant policy issues, visions of AI futures are communicated and used to increase public support and acceptance (cf. Inayatullah 2012; Callaghan and Schnell 2001). Policy documents yield valuable information for us to examine how the German government enacts its AI futures frames. In addition, we gather evaluation reports and press releases, in which AI futures frames are reinforced. All policy documents were retrieved from the official websites of the three German ministries BMBF, BMWi and BMAS. The search was restricted to publications including the keyword "artificial intelligence". Only articles, press releases, and reports were included in the data collection. The least recent documents included in the data collection date back to March 2018. In this month, the German Ministry for Education and Research (BMBF) announced its intention to strengthen its AI innovation alongside the French government which had just published its 150-page long national AI strategy (Villani 2018). The data collection was finished in November 2019 with the publication of the progress report on "One Year Artificial Intelligence Strategy of the Federal Government" (The Federal Government 2019). The final data collection amounts to 270 pages of documents consisting of five policy papers, two evaluation reports and twelve press releases (see Appendix 1 in supplementary file).

To reconstruct German newspaper coverage, we gathered newspaper articles from four leading German newspapers that reflect the diversity of the German media landscape. Firstly, two national, daily German newspapers, namely Die Welt and Die Tageszeitung (taz), were chosen to avoid either conservative or liberal bias. Secondly, the high-profile quality newspapers Frankfurter Allgemeine Zeitung (FAZ) and Die Zeit were included as both are known for their indepth investigations (Röper 2016). Additionally, they also represent contrasting political leanings, with $F A Z$ being considered as center-right, liberal-conservative and Die Zeit as left-liberal. It is anticipated that frames differ depending on the political leaning of the newspaper resulting in a more critical stance on the German government's AI strategy by taz and Die Zeit and a more supportive attitude by Die Welt and $F A Z$.

The sample of newspaper articles was constructed by a keyword search on the respective websites of the four news outlets. In a first step, articles directly commenting on the German government's "National Strategy for Artificial Intelligence" were selected to analyze how German newspapers frame the political vision of the German AI future. Regarding the content check of the selected newspaper articles, we concentrated on discussions of the development, application, and meaning of AI in Germany. To develop a more profound understanding, the search focus was enlarged to three key topics closely connected to AI futures: economy and labor, social affairs, and research. Moreover, these themes also represent the main fields of work of the responsible German ministries BMWi, BMAS and BMBF. The keywords "competition", "participation", and "innovation" in combination 
with "artificial intelligence" were used to find relevant articles. Articles with less than 100 words and interviews were excluded, as these do not provide sufficient information on the dominant AI futures frames promoted by German media outlets. The final selection includes 47 newspaper articles published between March 2018 and November 2019 to cover the same time frame as the policy documents (see Appendix 2). As all newspaper articles are originally published in the German language, citations were translated in English by both researchers.

To mirror the discourse on German AI futures, we conducted a content analysis of frames aiming at the "illumination of patterns and trends that are not immediately observable" (Saraisky 2015, p. 27). To make the identification of frames more comprehensible, we follow Matthes' and Kohring's approach to provide operational definitions of the four frame elements defined by Entman (Entman 1993; Matthes and Kohring 2008) (Scheme 1).

The problem definition of AI futures frames concerns the discussed risks and challenges of AI futures on the one hand and the benefits and chances on the other hand. Secondly, AI futures frames provide a cause diagnosis for the origin of expected risks and benefits. Here, three basic categories have been derived from literature: external influences, such as foreign competition; national qualities, such as scientific expertise; and the technological progress as an autonomous development. These three factors are mainly made responsible for threats and chances in the upcoming AI future. The third frame component refers to the evaluation of the upcoming changes, whether they are described as desirable, threatening, and/or probable. The last frame element defines the solutions suggested by the government and the media. Here, four measures were determined to be the most likely: the call for increasing investments to successfully compete in the race for AI leadership, the demand for intensified national and international cooperation, the request to foster the public

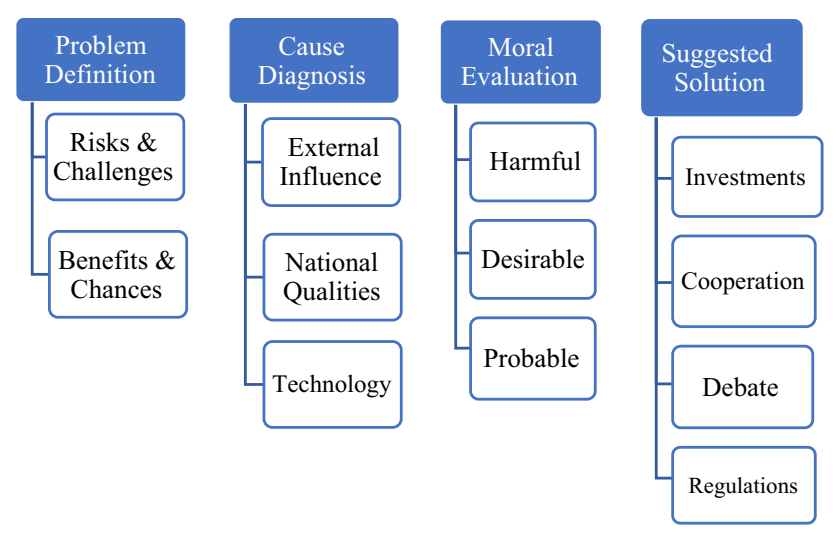

Scheme 1 The impact of AI futures on the German economy, society and research debate on AI futures, and the need for stricter legal regulations and ethical guidelines.

In the process of analysis, the collection of keywords was expanded, and typical examples are provided (see Appendix 3). Each policy document and each newspaper article was coded manually following an abductive approach that applied our ex-ante developed frames while still allowing new frames to emerge from the data (Gioia et al. 2012). In the analysis, we describe which AI futures frames stem from the ex-ante theoretical development, and we explain on which specific theoretical considerations the frames are based on. The coding was conducted by one main coder followed by a revision of the coding by the second author. We describe the frames in detail and provide illustrative quotes showing how the German government and the German media generate, diffuse, and mobilize ideas on German AI futures (Saraisky 2015).

\section{The German past as mirror of the German future}

The German government outlines an unambiguous AI future vision-a success story based on Germany's economic backbone. In its rhetoric, it calls for urgent implementation of its AI future vision to not lose competitiveness vis-à-vis other nations, which would allegedly result in diminishing German welfare. In its implementation vision, the German government puts its trust in Germany's industrial sector whose long-standing strength is to be maintained in the upcoming AI future. This is to be achieved via the renewal of an "AI made in Germany" and the German development of "ethical AI". In German newspaper coverage, the government's vision of a prosperous German AI economy leading to technological innovation - that is equated with social progressis amplified. However, German newspapers also uncover the mirror image of the German past in the envisioned AI future. The media criticize the German government's unwillingness to integrate new ways of shaping technology, life, and society in its German AI future vision and thereby open room for discussion of alternative AI futures.

\subsection{German Al as "key to the future"}

In its initiation of the quest for the German AI future, the German government constructs the frame of AI as key to Germany's future. This AI futures frame has been developed ex-ante based on the theoretical expectation that the German government-as well as other governments in the past (Augustine et al. 2019; Bourne 2019; Ossewaarde 2017) uses its political AI future vision to protect its interests in the future. The frame's main function is to increase the urgency for the AI future envisioned by the German government 
turning its AI strategy into the only possible future scenario. The German government declares that the "age of AI" has already arrived and that various AI technologies such as machine learning or algorithmic decision-making can be used to foster a noticeable social progress in the interest of all German citizens (The Federal Government 2018b). At the same time, the German government warns that "certain countries have already recognized the special potential of AI and have presented their own strategies (e.g. USA, China)" (The Federal Government 2018a, p. 3) and that the "the international race to attract talent, creativity, technology, data, and investment is rapidly picking up speed" (The Federal Government 2018b, p. 10). This portrayal shows how the German government defines Germany's future as an "arena of economic conquest" (Inayatullah 2012, p. 41). The German government's promise is that if all actors of German society act immediately, there is still hope for Germany to win the race for the AI future, and thereby safeguard German prosperity and security. The frame of AI as key to the German future communicates three central messages to the public: (1) The alleged "age of AI" is marked by a global competition for AI leadership; (2) Germany lags behind in the race for global AI leadership; and (3) Germany can still catch up and become a global AI leader if all relevant actors, including industries, workers, and citizens, are mobilized for realizing German AI leadership.

The frame of AI as key to the German future is initiated by the German government to provide clear orientation (permitting no ambiguity), justify immediate action, close off alternative German AI futures, and communicate commitment to winning the alleged battle for German AI leadership. While the government's frame incorporates a vision of Germany's future that is clear (namely, a future that is defined by $\mathrm{AI}$ ), the meaning of AI that the German government communicates is unclear. First, the German government uses the term AI as a "key technology" in an inconsistent way. Sometimes AI is claimed to be the key technology, sometimes specific AI applications, such as autonomous driving or text and data mining, are depicted as key AI technologies. In other cases, the German government emphasizes that AI applications pose high demands on already existing technologies and insists that only the combination of AI and other key technologies can leverage German opportunities in the future (The Federal Government 2018b, pp. 15-17). These diverse descriptions of AI blur the meaning of its actual impact on German society. Yet, its envisioning of the German AI future contains a clear message: as key to the German future, AI-and particularly German AI leadership-is indispensable. The German government provides no further explanation to what kind of German AI future is in the making: only the need for AI is emphasized. Thus, its German AI future frame reduces unclarity, even though the frame contains an ambiguous description of AI as key to the German future.

Moreover, the German government's frame shows how German AI future visions are transformed from possibilities into political promises and necessities (cf. Meyer 2019). In its endorsement of the "age of AI", the German government depicts AI as future and present simultaneously. AI not only allegedly determines the German future, but already controls the present-a present that is marked by Germany lagging behind in the global competition for AI leadership. The German government calls for immediate action, which it claims is vital for realizing a desirable German AI future. This call for action implies that there is no more time for publicly debating possible AI futures. The German government portrays its AI strategy as the only feasible way to realize the German AI future, and thereby closes down room for alternative discourses and visions. The central message is that thanks to the government's foresighted action and the innovative spirit of the German economy, the German AI future can still be realized in time. Hence, the German government presents its own visions of a desirable German AI future (a future marked by German AI leadership) as possible and attainable, which is a typical dimension for effective frames (cf. Meyer 2019).

The frame of AI as key to the German future is not the only AI futures frame that the German government initiates. It also constructs a futuristic image of German AI. That is, the German government not only claims that $\mathrm{AI}$ is key to the future, but it also insists that there is something uniquely German about AI in Germany. This alleged uniqueness of German AI is well exemplified by the following citation: "The Strategy of the Federal Government is also intended to help boost 'AI made in Germany', a special and specific approach to technology that focuses on creating benefits for the country and society." (The Federal Government 2018b, p. 10). The government's dominant message is that German AI, as contrasted with, say, Russian, Chinese or American $\mathrm{AI}$, is marked by "citizens first" (rather than government first or tech corporations first) and "people-centered" (rather than state-centered or company-centered). In this frame, AI is envisioned to foster German citizens' social participation, their freedom of action, and their protection of privacy, thereby reinforcing certain longstanding German political, social, and cultural values (The Federal Government 2018b, p. 37). The German government shows an acute awareness that such values can be easily destroyed and have been so frequently destroyed in recent German history. Hence, these values must be protected, including in technology design via "ethics by design".

Yet, in the frame of German AI, AI is not only an issue of German values and ethics, but it is also an economic enterprise. To harmonize the notion of "people-centered" AI with the necessity of a thriving German AI economy, the 
government fosters the development of "consumer-enabling technologies (e.g. legal tech providing advice to consumers) that will support consumers in their purchasing decisions" (The Federal Government 2018b, p. 16). Noticeably, the development of a German AI economy is by no means secondary. As the German government puts it, "we want [...] AI-based business models to be developed in Germany and to become new top exports." (The Federal Government 2018a, p. 2). Consequently, the development of German AI as key to Germany's AI future is not only presented as an obligation of the German government: Germany's AI future is defined as a task for German society, including German companies, as a whole, to promote economic prosperity and growth. This also implies that current economic power constellations are sought to be maintained in the AI future. For instance, the German government declares that the reason for Germany's high competitiveness lies particularly in the unique strength of German medium-sized businesses. In contrast to the giant US and Chinese tech firms, the German AI businesses need to be protected and promoted in the German AI future to compete on a global scale (The Federal Government 2018b, p. 8). Hence, the frame of German AI turns the German making of AI technologies into a national mission to safeguard a flourishing growth-oriented German AI economy.

While the German government's frame of AI as key to the German future blurs the meaning of AI, its frame of German AI blurs the role of German values in shaping the German AI future. The government claims that "AI made in Germany" represents the German economic and social structure, especially the German value system. Yet, it fails to clarify how these German values determine the specific understanding of AI and dealing with AI in Germany. The government's frame of German AI provides orientation and motivation to create a German AI future (cf. Meyer 2019). "Made in Germany" is a globally known, incontrovertible quality label (Statista 2017), which implies that AI technologies that are developed, tested, and produced in Germany are thought to be reliable and safe. Expressed differently, the government's frame of German AI reduces concerns about AI technologies and strengthens the perception of $\mathrm{AI}$ as a national mission of making high-quality, trustworthy AI technologies that keep Germany wealthy. Simultaneously, the frame clearly locates the responsibility to create an "AI made in Germany" in the hands of the German industry, which consequently holds the key for defining the meaning of cultural, ethical, trustworthy, reliable, and safe AI.

\subsection{The framing of the making of the German Al future}

In its vision of implementing its AI strategy, the German government frames AI as panacea for present and future problems. This AI futures frame has been developed based on the theoretical background and represents the widespread quotation of technological and social progress that is repeatedly used in envisioning and promoting technology-driven futures (Callaghan 2018; Williams 2006). As suggested by theory the frame's central function is the creation of hope and the mobilization resources. In its framing of the upcoming AI future, the German government presents the opportunities of AI as limitless. The government promises nothing less than a better understanding of complex natural and economic systems and societal progress in the German AI future (The Federal Government 2018b, p. 17). In the framing of AI as panacea, potential risks of AI technologies for German society are presented to emerge from third parties (mostly other AI leaders such as China, the USA or Israel are identified). According to the German government, these AI leaders might misuse the potential of AI to gain unauthorized access to secret data. Consequently, the German government's overall solutions for dangers in the German AI future is anticipation, including safety precautions and "setting standards" by means of "ethics by, in, and for design" (The Federal Government 2018b, p. 37). Lastly, the occurrence of tangible risks such as increasing discrimination and inequality is outsourced to foreign countries which are not protected by Germany's high-quality AI. The framing of AI as a panacea for potential risks (e.g. permanent electronic surveillance, the manipulation and falsification of information or increasing discrimination by algorithmic decision-making) has two central elements. On the one hand, the German government indicates the diversity of possible AI future scenarios-including the threat of dystopian or Orwellian AI futures-and on the other hand, it makes a desirable German AI future conditional on the realization of its policy strategy.

In its implementation vision, the German government frames AI as a cure-all for complex global challenges related to climate change and natural resource management, the future of energy supply and agriculture (The Federal Government 2018b, p. 17). According to the German government, the benefits of AI lie in various scientific fields ranging from biotechnology to mobility, as well as in economic opportunities for the cultural, media and creative industry. In general, it declares that AI technologies must be used to increase the net domestic product in the German AI future (The Federal Government 2018a). To put it in the words of the German Minister of Economic Affairs Peter Altmaier: "AI is not any innovation-it is a basic innovation which will change and improve our economy and life profoundly" (BMAS 2018, p. 1). In such enactment of the frame of AI as a panacea, potential and opportunities for progress are mentioned, without being clear about the meaning of "revolutionary" in AI or about what the beneficial applications to improve citizens" 
welfare profoundly may be. Even if no concrete benefits of $\mathrm{AI}$ are envisioned, in the eyes of the German government it is clear that, to shape a desirable German AI future, "AI needs to be viewed, desired and shaped as an opportunity" (The Federal Government 2018b, p. 45). Therefore, the German AI future is not only a utopian possibility, but a political-administrative necessity whose realization demands the collective approval, discipline, and efforts of the whole German nation.

In the government's frame of AI as panacea for potential risks, uncertainty about the possible downsides of $\mathrm{AI}$ - such as the intensification of filter bubbles, the increasing invasion of privacy and their impact on democratic society-is framed as a menace. In the vision of the German government, future AI developments must be anticipated as best as possible to guarantee that AI technologies serve German society (The Federal Government 2018b, p. 4). The German government conveys the belief that if enough information on the current and future development of AI is collected by so-called "future centers" set up by the government, the desirable German AI future can easily be implemented (in cooperation with the German industry). Yet, the government declares that "It is important to make use of these possibilities [...] with an awareness of any ethical limits and dangers to our free, democratic society" (The Federal Government 2018b, p. 44). Here, a balanced view on AI futures is presented as the German government acknowledges that AI can have downsides for German society. However, overcoming these dangers is presented as an issue of political-administrative control and not as one of public debate on the definition of ethical limits or possible dangers. For instance, Peter Altmaier states that "to develop and to control AI [...] is a key concern for Germany" (BMAS 2018, p. 1). He promises to create the necessary regulatory framework for the German AI future.

However, developing standards for $\mathrm{AI}$ and discussing its (ethical) limits of $\mathrm{AI}$ is not declared to be the task of the German government. The Germany's industrial sector is deemed to be responsible for the making of German ethical AI: "developing standards is primarily up to the private sector, not the state" (The Federal Government 2018b, p. 39). Especially, the German car industry is demanded to incorporate "ethics by design" in the development of autonomous driving. In return, the German industry's political bargaining power is fostered by involving more business representatives in standardization committees. Hence, uncertainty regarding Germany's future economic position is framed as a central risk in the German AI future, and is to be eliminated by building a stronger, more competitive German AI economy. In contrast, the German Data Ethics Commission directly addresses the conflict between public and corporate interests that most likely arises with a growing German AI economy. The Commission declares that "a balance must be found between the state's responsibility for creating and enforcing framework conditions, which ensures trust, and the freedom, autonomy and responsibility of users and others affected by the new technologies on the one hand, and the forces of the market and competition on the other hand." (German Data Ethics Commission 2018, p. 4).

In its implementation vision, the German government warns that "It is important to ensure that AI applications developed by industrialized countries are not discriminatory or unsuitable for users in developing countries" (The Federal Government 2018b, p. 42). These discriminatory practices concern, for example, automatic facial recognition software whose error rate is still many times higher when analyzing faces not belonging to the ethnic majority, which is typically white and male. Thereby, the risk of being unfairly blamed increases significantly for ethnic minorities (West et al. 2019). According to the government, this inappropriateness might be caused by wrong or missing training data for algorithms and needs to be obviated by improved algorithms that are trained with "appropriate data". This appropriate data is generated by increasing the diversity of the training data which means including more photos of Asians, people of color, disabled people, or women in the data sets. However, the German government's approach demonstrates that there is no intention to question the particular origin of an algorithm's discriminatory practice. Algorithms are developed and used for specific purposes which are often determined by monetary interests. Each data analysis system is programmed by individuals who integrate their prejudices and biases into the programmed code. Consequently, these systems cannot be objective. As West et al. point out: "'diversifying' the dataset is not a de facto solution and may in fact exacerbate the problem by legitimizing harmful technologies." (West et al. 2019, p. 19). This issue is not discussed in the German government's AI strategy and, consequently, today's inequalities in power structures concerning, for instance, false suspicions or accusations are maintained and even reinforced in the AI future.

Additionally, the German government suggests that there is a higher potential for abuse in countries that-in contrast to Germany-have, in the absence of a well-functioning rule of law, insufficient privacy policies or protective mechanisms (The Federal Government 2018b, p. 42). The foresighted policy measures of the German government are supposed to protect German society from cyberattacks launched by third parties like non-EU states or private hackers-but only if the outlined AI strategy is realized. Again, the occurrence of dangers-such as the violation of privacy or data security or the manipulation and falsification of information-is dismissed as risks are prevented before their emergence. The government communicates the belief that the possibility of emerging dangers predominately occurs in far-off German AI futures. In its implementation vision, the unique quality 
of German AI seems to significantly lower the possibility of abuse of AI in Germany. Expressed differently, $\mathrm{AI}-$ and German AI in particular-is framed as cure-all for possible difficulties in the "age of AI". Again, the German Data Ethics Commission disagrees and strongly emphasizes the need to provide an educational framework "in which individuals and institutional actors can acquire sufficient digital and media literacy and the ability to reflect critically on how to deal with technical innovation" (German Data Ethics Commission 2018, p. 3). However, this particular willingness to create a critical public that questions emerging AI technologies is not reflected in the German government's AI strategy.

The German implementation vision is marked by an unshattered belief in the economic opportunities that AI offers - opportunities that are to be seized via public-private partnerships between the German government and the German industry. The central political-administrative message is that the German government will responsibly prepare for the German AI future by setting a regulatory framework to safeguard German society's rights to informational self-determination, privacy, and data protection. The German industrial sector is responsible for developing German AI that not only represents a strong backbone of Germany's economy but simultaneously protects society from harmful, potentially discriminating AI technologies such as permanent surveillance or opaque algorithm-based decision-making. "Ethics by design" are supposed to be the trademark of an "AI made in Germany", with the German industry holding the key to the making and safeguarding of German ethical standards (The Federal Government 2018b, p. 39). Indeed, in the government's implementation vision, the ethics of AI are to be determined by German industry in the first place and not by democratic institutions or academia. The German government communicates the belief that the beneficial, peoplecentered use of AI can only be secured in Germany if the government's AI strategy is implemented immediately. In foreign countries that have less responsible governments, no well-functioning rule of law, and less innovative industries, the impact of AI might be more Orwellian.

\subsection{Reinforcement and contestation: two rival media frames}

In the mainstream news coverage of the German AI future, the government's German AI frames are reinforced (cf. Wolfe et al. 2013). In contrast to theoretical expectations, no significant differences in the media framing by newspapers associated with the governing coalition (FAZ and Die Welt) and the political opposition ( $t a z$ and ZEIT) could be found. Thus, we treat the media monolithically in our analysis. The German media define AI as a key technology with a disruptive potential tantamount to the invention of electricity (FAZ 2). According to taz, "the rapid progress of AI electrifies researchers and politics" (taz 26); Die Welt claims that like electricity in the past, "AI will soon change the world forever" (WELT 39). German newspapers present the German AI future as an inevitable destiny that will affect all areas of life within a couple of years. They point at the allegedly immense worldwide competition for AI leadership (FAZ 3, taz 34, WELT 39, ZEIT 17). As reported by Die Zeit: "a digital arms race has arisen in which many states participate with ambitious strategies" (ZEIT 24). However, it is widely communicated that the alleged race for AI hegemony is not yet decided. An unequivocal appeal for German AI is made (FAZ 2, WELT 41). German newspapers stress that an "ethical, humancentered AI needs to be developed by public discourse" (ZEIT 24). Yet, it is emphasized that "doubters must not control the debate about new technologies", but, instead, in such a public discourse "we need to focus more on the chances of AI in Europe" (WELT 39). Die Welt warns that the "triumphal march of Made in Germany is jeopardized" and demands a "360 degrees innovation offense", so as to make the German industrial location ready for the German AI future (WELT 38).

German newspapers suggest that more German AI will make the German economy strong in the future. They claim that a lack of public and private investments in $\mathrm{AI}$ is a serious error which might lead to the German economy missing the AI future (ZEIT 14, 24). German newspapers communicate the central message that Germany must immediately prepare for the inevitable AI future. In line with the government, all four newspapers declare immediate action to be essential to not miss the future. The media debate focuses on Germany's economic future and AI is framed as a strategic resource for which to compete internationally. The equation of technological development and social progress is amplified in the newspaper coverage. In addition, according to the media, the central objective of the German AI strategy must be the continuation of Germany's successful economic history, preferably via the old trademark "Made in Germany".

Yet, in spite of such media reinforcement of the German government's AI futures frames, the German media's assessment of the government's frames is not completely uncritical. While German newspapers generally praise the government's political will to make Germany the worldwide leading AI location, they denounce the absence of concrete policy measures. The newspapers criticize that the sketchedout way is vague, half-baked and unsorted (FAZ 2, ZEIT 22) and address the discrepancy between the government's highly ambitious goals and the vagueness of the planned measures (taz 26, WELT 38). In addition, the media partly expose the government's German AI futures frames. For instance, FAZ declares that "the keyword AI serves as a placeholder for the equation: successful innovation = welfare generating future $=$ political stability" (FAZ 7). In addition, 
the media scrutinize the umbrella term $\mathrm{AI}$ and the functioning of specific AI applications like algorithmic decisionmaking and machine learning (taz 31, WELT 47, ZEIT 18). By framing the German government's AI strategy as a black box, the media imply that the German AI future is indefinite and open. The image of a clear, infallible plan is blurred and the government's actions appear less strategic and self-evident.

Moreover, German media tend to suggest that the envisioning of AI futures is guided by political interests. The German AI future is declared to be a story in the first place (ZEIT 15). German newspapers highlight that for the attainment of one particular German AI future, anxiety about German decline or regress serves as an action engine. According to Die Zeit, the government's warning of Germany's economic decline is a strategic action. It claims that the narrative of Germany falling behind other political powers in digital transformation is outdated (ZEIT 15).

Furthermore, the media attempt to demystify AI by explaining its limits and the specific ways in which AI technologies can increase structural discrimination (taz 31, WELT 47, ZEIT 18). For instance, the widespread idea that discrimination of algorithmic decision-making, for example in the field of human resources, crime prevention (predictive policing) or advertising, can be eliminated if only datasets are repaired by more "accurate" data, is rejected. Die Zeit, for instance, emphasizes that "the developed software is always marked by the social reality-including the stereotypes and prejudices - of the developers" (ZEIT 18, see also West et al. 2019). Here, the German media explain the functioning of algorithms that reproduce forms of structural discrimination that have already occurred throughout centuries. In other words, the German media's frame of AI as a black box strongly underlines the ambiguity inherent to German AI futures. German newspapers address the vagueness of the German government's AI strategy and the obscurity of the functioning of AI technologies.

A second prevalent frame in the media coverage of German AI futures is the portrayal of German ethical AI as a fig leaf. German newspapers not only present the German government's AI strategy as a black box, but they also point at the deeply rooted structural imbalances in power constellations in AI technologies that the German government does not discuss. Such problematic German power structures make a German "ethical AI" made within such power structures problematic. For example, the conservative newspaper FAZ claims that "ethical AI becomes the justification apparatus of the status quo and the diversionary tactic from more extensive political questions regarding the existing balance of power, wealth distribution, democracy, and the shaping of the future" (FAZ 7). This citation demonstrates how FAZ accuses the German government of avoiding fundamental questions of future political design and societal organization, as it pursues to maintain established power constellations.

German newspapers consider "ethics" as envisioned by the German government, and given in the hands of German industry, as a political instrument to create trust to overcome the threat of a skeptical public, and to foster the industry's competitiveness (FAZ 12, ZEIT 19). For instance, German media declare that "the story of trustworthy AI is a marketing narrative made up by industry", emphasizing that "customers don't buy products in which they do not trust" (FAZ 12). Moreover, Die Zeit clarifies that the automation of ethics that "ethical AI" suggests is impossible as "ethical decisions are far too complex to be reflected in software systems" (ZEIT 18). In other words, German media reveal that the notion of "ethical" or "human-centered" AI as propagated by the German government and German industry is a governmental tactic and marketing strategy for increasing public support and sales. This strategy ultimately results in the reinforcement of the problematic German politicalindustrial status quo.

The German media frame German ethical AI as a fig leaf, that hides underlying power structures and vested interests in a tech industry-dominated Germany, contains two central elements (Moorstedt 2019; Thiel 2019). First, the media point out that the German AI future is determined by strategic decisions and that the development of $\mathrm{AI}$ is not an unalterable, autonomous process. German newspapers highlight that fundamental changes (e.g. regarding the political rule, the balance of power or wealth distribution) are only possible if they are demanded and steered by political-administrative elites. The fundamental conflict between corporate and societal interests is addressed directly, which spotlights the basic question of who decides on possible AI futures. By criticizing the German government for framing the German AI future as the mere adaptation to disruptive technologies and not as a possibility for design, the media stress that an actual process of future-making exists (Meyer 2019). The media describe the profound changes of the AI future as the possibility and necessity to question the very foundations of contemporary German society. This opportunity for change in Germany's societal organization is disregarded by the German government, which does not encourage any transformation in today's German power constellation. Thus, the German government's AI future vision is unmasked as being conservative by the media, which demonstrates that no radical, societal vision exists. Instead, the government's main aim is to protect its hegemonic position. To put it differently, the media frame of ethical AI as a fig leaf points out how the government shifts attention away from today's and the future's problems of power imbalances and corresponding under-democratization in Germany (Table 1). 
Table 1 Summary of German AI Futures Frames

\begin{tabular}{|c|c|c|c|}
\hline Frame & Keywords & Effect & Problematic issues \\
\hline $\mathrm{AI}$ as key to the future ${ }^{\mathrm{a}}$ & Technology, potential, competition & $\begin{array}{l}\text { Increase necessity for AI future, } \\
\text { create urgency, reduce uncertainty }\end{array}$ & $\begin{array}{l}\text { Inconsistency, ambiguous description } \\
\text { of AI, Closing down public debate }\end{array}$ \\
\hline $\mathrm{AI}$ as German $\mathrm{AI}$ & Participation, values, industry & $\begin{array}{l}\text { Masking ambiguity of AI, provide } \\
\text { security and orientation, reduce } \\
\text { concerns, secure AI funding }\end{array}$ & $\begin{array}{l}\text { Blurred role of values, discouraging } \\
\text { debate, AI defined by industry }\end{array}$ \\
\hline $\mathrm{AI}$ as panacea $\mathrm{a}^{\mathrm{a}}$ & Challenges, chances, anticipation & $\begin{array}{l}\text { Illustrate diverse effects of AI, cre- } \\
\text { ate hope, mobilize action }\end{array}$ & $\begin{array}{l}\text { Dependency on government's strat- } \\
\text { egy, unclarity about AI's meaning } \\
\text { and benefits }\end{array}$ \\
\hline Uncertainty as main menace & $\begin{array}{l}\text { Sovereignty, control, (In)depend- } \\
\text { ence }\end{array}$ & $\begin{array}{l}\text { Future as political-administrative } \\
\text { challenge, mobilize citizens' } \\
\text { participation }\end{array}$ & $\begin{array}{l}\text { Future portrayed as calculable, } \\
\text { distracting attention away from } \\
\text { concrete impact of AI }\end{array}$ \\
\hline $\mathrm{AI}$ as black box & Vagueness, uncertainty, change & $\begin{array}{l}\text { Stressing openness of AI futures, } \\
\text { helping to make sense of } \mathrm{AI}\end{array}$ & $\begin{array}{l}\text { Strategy appears less evident, reveal- } \\
\text { ing political and corporate interests }\end{array}$ \\
\hline Ethical AI as fig leaf & $\begin{array}{l}\text { Distraction, status quo, vested } \\
\text { interests }\end{array}$ & $\begin{array}{l}\text { AI futures as outcome of political } \\
\text { decisions, underlining process of } \\
\text { future-making }\end{array}$ & $\begin{array}{l}\text { Addressing conflict of interests: } \\
\text { corporate versus societal }\end{array}$ \\
\hline
\end{tabular}

${ }^{a}$ Ex-ante developed frame derived from the theoretical background

\section{Concluding remarks}

The German government frames the German AI future and its impact on the German economy and society as the given result of an autonomous technological development that is expected to deliver a desirable German future. The German government remains vague in its description of benefits and risks of AI. For example, it mentions increasing efficiency of health systems or the "humanization of labor" on the one hand and newly emerging threat scenarios for internal and external security on the other hand. Still, the German government provides frames for channeling public understanding of AI's impact on the economy and society (Meyer 2019; van Hulst and Yanow 2016; Wolfe et al. 2013). According to the German government, the German AI future is an unquestioned reality to which the entire German nation must adapt. It claims that as no German future exists without AI ("AI as key to the future"), accommodating AI-determined realities is the only option. According to the German government, the preparation for the German AI future is the task of the German nation as a whole ("German AI"), and participation is equated with the approval of and the adaptation to the new "age of AI". This means that German citizens are expected to adjust their role within the framework provided by the German government. AI is framed as the cure-all for present and future problems in Germany ("AI as panacea"). The greatest danger in the German AI future stems from insufficient anticipation, inaction, and the threat of a declining German economy ("Uncertainty as main menace").

In German newspaper coverage, the government's framing regarding the economic aspects of the German AI future is endorsed. In German newspapers, the economic rule of society is presented as inevitable, both in the present and in the upcoming AI future. No far-reaching, structural changes of the German economy and its place in German society are foreseen: German society continues to be dominated by German industry. However, the consequences of the AI future on society are framed differently by German newspapers. The media frame German AI futures as the deliberate outcome of political decision-making, not as the result of an uncontrollable development (cf. Callaghan and Schnell 2001; Glazier and Boydstun 2012). German newspapers open room for new outlooks. They provide hope for change in established power structures and motivation for political action in shaping alternative futures. German media unmask the envisioned AI future of the German government as a strategic measure employed for upholding underlying political-administrative-industrial power constellations. The media spotlight the inherent vagueness of the government's AI future vision ("AI as a black box") and seek to present a clearer image of possible AI futures. The media directly criticize the government's strategic use of the future ("ethical AI as a fig leaf"). By questioning basic assumptions concerning the balance of power in the future, the media show that there is little political-administrative willingness to design German AI futures that significantly diverge from the past or present.

In the German government's envisioning of the AI future, the German past is projected on the German future. Like in the past, the welfare of German society is dependent on Germany's industry that is now called to compete in the global AI economy. German industry is demanded to steer AI development, the design, and the use of AI in realizing the German AI future. The responsibility to create a regulatory framework for the development and use of AI technologies is placed in the hand of the German industry. 
In line with neoliberal discourse, the invisible hand of the AI market economy is guiding Germany's way to the "age of AI" (Bourne 2019; Irwin and White 2019). In preparing for the promised AI future, it is indispensable that German companies take on AI leadership to set worldwide AI standards that correspond to an "AI made in Germany". The German government's constant emphasis of the German AI economy built up by an innovative German industry reveals that the established social order with its established power relationships is expected to survive ad infinitum. No past or future technology — even with such a disruptive potential like AIwill ever alter the very foundations of the German order. Even if the basic definition of humanity is questioned by the development of "strong" or "transformative" AI (Dafoe 2018; Gill 2019; Gruetzemacher and Whittlestone 2020; Totschnig 2019), German capitalist rule remains untouched. To make the German nation an "AI leader" signifies maximizing the economic turnover of AI technologies, which requires a leading role for the German industry in the making of the German future. Thus, by mirroring Germany's economic success story of "Made in Germany" in the German AI future, politics and industry ensure that even worldshaking inventions such as AI do not bring about serious changes altering societal organization.

Taking a broader perspective on the political and media discourse of AI and society, our findings imply that AI remains an elitist project steered by political-administrative and corporate interests. We could identify few political efforts to help the public making sense of AI and possible future scenarios that are supposedly defined by AI technologies. Our findings provide another example of Augustine et al.'s conclusion that "the constant imagination and pursuit of distant futures has been repeatedly identified as a central dynamic of capitalism" (Augustine et al. 2019, p. 1956). This imagination and amplification of (AI) futures manifests existing power imbalances. As observed by Jasanoff "inequality—not only as access but even more of anticipation-emerges as an unresolved ethical and political barrier to the just governance of technological innovation" (Jasanoff 2016, p. 256). Further research on dominant AI future visions and the frames integral to them is needed to examine political, corporate, and societal interests in detail. The ultimate aim of this research should be to finally start an open debate on the use of technological innovation in the creation of possible futures that are, first and foremost, filled by public interests.

Supplementary Information The online version contains supplementary material available at https://doi.org/10.1007/s00146-021-01161-9.

Open Access This article is licensed under a Creative Commons Attribution 4.0 International License, which permits use, sharing, adaptation, distribution and reproduction in any medium or format, as long as you give appropriate credit to the original author(s) and the source, provide a link to the Creative Commons licence, and indicate if changes were made. The images or other third party material in this article are included in the article's Creative Commons licence, unless indicated otherwise in a credit line to the material. If material is not included in the article's Creative Commons licence and your intended use is not permitted by statutory regulation or exceeds the permitted use, you will need to obtain permission directly from the copyright holder. To view a copy of this licence, visit http://creativecommons.org/licenses/by/4.0/.

\section{References}

Augustine G, Soderstrom S, Milner D, Weber K (2019) Constructing a distant future: imaginaries in geoengineering. Acad Manag $\mathbf{J}$ 62(6):1930-1960. https://doi.org/10.5465/amj.2018.0059

Beck K (2018) Die publizistischen Medien. In: Beck, Klaus (eds) Das Mediensystem Deutschlands. Springer, Strukturen

Berendt B (2019) AI for the Common Good!? Pitfalls, challenges, and ethics pen-testing. Paladyn 10:44-65. https://doi.org/10.1515/ pjbr-2019-0004

Blümel C (2018) Translational research in the science policy debate: a comparative analysis of documents. Sci Public Policy 45(1):24-35. https://doi.org/10.1093/scipol/scx034

BMAS (2018) Digitaler Wandel Eröffnet Chancen. https://www.bmas. de/DE/Presse/Meldungen/2018/digitale-plattform.html

BMBF (2018) Künstliche Intelligenz Intelligent Nutzen. https://www. bmbf.de/de/kuenstliche-intelligenz-intelligent-nutzen-5936.html

BMWi (2015) Industrie 4.0 und Digitale Wirtschaft. https://www. bmwi.de/Redaktion/DE/Publikationen/Industrie/industrie-4-

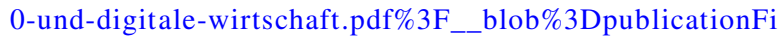
le $\% 26 \mathrm{v} \% 3 \mathrm{D} 3$

Bourne C (2019) AI Cheerleaders: public relations, neoliberalism and artificial intelligence. Public Relat Inq 8(2):109-125. https ://doi.org/10.1177/2046147X19835250

Brennen JS, Howard PN, Nielsen RK (2018) An Industry-Led Debate: how UK media cover artificial intelligence. Reuters Institute for the Study of Journalism, Oxford

Cacciatore MA, Scheufele DA, Iyengar S (2016) The end of framing as we know it and the future of media effects. Mass Commun Soc 19:7-23. https://doi.org/10.1080/15205436.2015.1068811

Callaghan CW (2018) Surviving a technological future: technological proliferation and modes of discovery. Futures 104:100-116. https://doi.org/10.1016/j.futures.2018.08.001

Callaghan K, Schnell F (2001) Assessing the democratic debate: how the news media frame elite policy discourse. Polit Commun 18(2):183-213. https://doi.org/10.1080/105846001750322970

Carbonell J, Sánchez-Esguevillas A, Carro B (2016) The role of metaphors in the development of technologies. The case of artificial intelligence. Futures 84:145-153. https://doi.org/10.1016/j.futur es.2016.03.019

Caruso L (2018) Digital innovation and the fourth industrial revolution: epochal social changes? AI Soc 33:379-392. https://doi. org/10.1007/s00146-017-0736-1

Cath C, Wachter S, Mittelstadt B, Taddeo M, Floridi L (2017) Artificial Intelligence and the 'Good Society': the US, EU and UK approach. Sci Eng Ethics 24:505-528. https://doi.org/10.1007/ s11948-017-9901-7

Cobb MD (2005) Framing effects on public opinion about nanotechnology. Sci Commun 27(2):221-239. https://doi. org/10.1177/1075547005281473 
Dafoe A (2018) AI Governance: a research agenda. Centre of the Governance of AI. Future of Humanity Institute. University of Oxford. https://www.fhi.ox.ac.uk.

Donk A, Metag J, Kohring M, Marcinkowski F (2012) Framing emerging technologies: risk perceptions of nanotechnology in the German Press. Sci Commun 34(1):5-29. https://doi. org/10.1177/1075547011417892

Druckman JN, Bolsen T (2011) Framing, motivated reasoning, and opinions about emergent technologies. J Commun 61(4):659688. https://doi.org/10.1111/j.1460-2466.2011.01562.x

Entman RM (1993) Framing: toward a clarification of a fractured paradigm. J Commun 43(4):51-58. https://doi. org/10.1111/j.1460-2466.1993.tb01304.x

European Commission (2020) White paper. On artificial intelligence: a European approach to excellence and trust. https://ec.europ a.eu/info/sites/info/files/commission-white-paper-artificial-intel ligence-feb2020_en.pdf.

Floridi L (2019) What the Near Future of Artificial Intelligence Could Be. Philosophy \& Technology 32:1-15. https://doi. org/10.1007/s13347-019-00345-y

Gansser O (2019) Künstliche Intelligenz in Deutschland-Meinungen und zukünftige Einschätzungen. FOM Sommerumfrage 2019. ifes Institut für Empirie \& Statistik

German Data Ethics Commission (2018) Recommendations of the Data Ethics Commission for the Federal Government's Strategy on Artificial Intelligence. https://www.bmjv.de/SharedDocs/Downl oads/DE/Ministerium/ForschungUndWissenschaft/DEK_Empfe hlungen_englisch.pdf?_blob=publicationFile \&v $=3$

Gill KS (2018) Artificial Intelligence: looking though the Pygmalion Lens. AI Soc 33:459-465. https://doi.org/10.1007/s0014 6-018-0866-0

Gill KS (2019) Artificial intelligence: against humanity's surrender to computers. AI Soc 34:391-392. https://doi.org/10.1007/ s00146-018-0873-1

Gioia DA, Corley KG, Hamilton AL (2012) Seeking qualitative rigor in inductive research: notes on the gioia methodology. Org Res Methods 16(1):15-31. https://doi.org/10.1177/10944 28112452151

Glazier RA, Boydstun AE (2012) The President, the press, and the war: a tale of two framing agendas. Polit Commun 33:428-446. https://doi.org/10.1080/10584609.2012.721870

Goffman E (1974) Frame analysis. Harper, New York

Gruetzemacher R, Whittlestone J (2020) The transformative power of artificial intelligence. Comput Soc 1912:00747

Haynes C, Merolla JL, Ramakrishnan SK (2016) Media framing and effects on public opinion. In: Haynes C, Merolla JL, Ramakrishnan SK (eds) Framing immigrants. News coverage, public opinion, and policy. Russel Sage, New York, pp 16-40

van den Heijkant L, Vliegenthart R (2018) Implicit frames of CSR: the interplay between the news media, organizational PR, and the public. Public Relat Rev 44:645-655. https://doi. org/10.1016/j.pubrev.2018.05.007

Horowitz MC (2018) Artificial intelligence, international competition, and the balance of power. Texas Natl Secur Rev 1(3):3757. https://doi.org/10.15781/T2639KP49

van Hulst M, Yanow D (2016) From policy "frames" to "framing": theorizing a more dynamic, political approach. Am Rev Public Admin 46(1):92-102. https://doi.org/10.1177/0275074014 533142

Inayatullah S (2008) Six pillars: futures thinking for transforming. Foresight 10(1):4-21. https://doi.org/10.1108/146366808108559 91

Inayatullah S (2012) Futures studies: theories and methods. In: BBVA (ed) There's a future: visions for a better world. https://www. bbvaopenmind.com/wp-content/uploads/2013/01/BBVA-OpenM ind-Book-There-is-a-Future_Visions-for-a-Better-World-1.pdf.
Irwin R, White TH (2019) Decolonising technological futures: a dialogical tryptich between Te Haumoana White, Ruth Irwin, and Tegmark's Artificial Intelligence. Futures 112:102431. https://doi. org/10.1016/j.futures.2019.06.003

Jasanoff S (2016) The ethics of invention: technology and the human future. W.W. Norton \& Company, New York

Jasanoff S (2018) Just transitions: a humble approach to global energy futures. Energy Res Soc Sci 35:11-14. https://doi.org/10.1016/j. erss.2017.11.025

Jasanoff S, Kim S (2015) Dreamscapes of modernity: sociotechnical imaginaries and the fabrication of power. The University of Chicago Press, Chicago, London

Kim J, Akin H, Brossard D, Xenos M, Scheufele DA (2017) Selective perception of novel science: how definitions affect information processing about nanotechnology. J Nanopart Res 19(5):167. https ://doi.org/10.1007/s11051-017-3837-3

Kinkartz S (2019) Die Deutschen und die Künstliche Intelligenz. Deutsche Welle. https://www.dw.com/de/die-deutschen-und-diek\%C3\%BCnstliche-intelligenz/a-51813343.

Kohring M, Matthes J (2002) The face(t)s of biotech in the nineties: how the German press framed modern biotechnology. Public Understand Sci 11:143-154. https://doi. org/10.1088/0963-6625/11/2/304

Krantz J (2012) The past and present as mirror of the future. In: Brunning H (ed) Psychoanalytic reflections on a changing world. Karnac, London

Lauterbach A (2019) Artificial Intelligence and policy: quo vadis? Digit Policy Regul Gov 21(3):238-263. https://doi.org/10.1108/ DPRG-09-2018-0054

van Lente H, Rip A (1998) The rise of membrane technology: from rhetorics to social reality. Soc Stud Sci 28(2):221-254. https://doi. org/10.1177/030631292828002002

Ligtvoet A, Cuppen E, Di Ruggero O, Hemmes K, Pesch U, Quist J, Mehos D (2016) New future perspectives through constructive conflict: exploring the future of gas in the Netherlands. Futures 78-79:19-33. https://doi.org/10.1016/j.futures.2016.03.008

Magin M, Geiß S (2019) Beyond time and space: the impact of autonomy from politics and commercialization pressure on mediatization in German and Austrian newspapers-a multilevel approach. Polit Commun 36(4):543-564. https://doi.org/10.1080/10584 609.2019 .1608605

Makridakis S (2017) The forthcoming Artificial Intelligence (AI) revolution: its impact on society and firms. Futures 90:46-60. https:// doi.org/10.1016/j.futures.2017.03.006

Matthes J, Kohring M (2008) The content analysis of media frames: toward improving reliability and validity. J Commun 58(2):258 279. https://doi.org/10.1111/j.1460-2466.2008.00384.x

Metze T (2018) Framing the future of fracking: Discursive lock-in or energy degrowth in the Netherlands? J Clean Prod 197(2):17371745. https://doi.org/10.1016/j.jclepro.2017.04.158

Meyer U (2019) The emergence of an envisioned future. Sensemaking in the case of "Industrie 4.0" in Germany. Futures 109:130-141. https://doi.org/10.1016/j.futures.2019.03.001

Moorstedt M (2019. Das Silicon Valley kauft sich ein Gewissen. Ethik bei Tech-Unternehmen. Süddeutsche Zeitung. https://www.suedd eutsche.de/meinung/silicon-valley-ethik-kommissionen-feigenblat $\mathrm{t}-1.4399509$.

Olesen K (2014) Implications of dominant technological frames over a longitudinal period. Inform Syst J 24(3):207-228. https://doi. org/10.1111/isj.12006

Ossewaarde M (2017) Unmasking scenario planning: the colonization of the future in the "local governments of the future" program. Futures: the journal of policy. Plan Future Stud 93:80-88. https:// doi.org/10.1016/j.futures.2017.07.003

Ossewaarde M (2019) Digital transformation and the renewal of social theory: unpacking the new fraudulent myths and misplaced 
metaphors. Technol Forecast Soc Chang 146:24-30. https://doi. org/10.1016/j.techfore.2019.05.007

Ossewaarde M, Gülenç E (2020) National varieties of AI discourses: myth, utopianism and solutionism in West European policy expectations. Computer 53(11):53-61

Ouchchy L, Coin A, Dubljevic V (2020) AI in the headlines: the portrayal of the ethical issues of artificial intelligence in the media. AI Soc 35:927-936. https://doi.org/10.1007/s00146-020-00965-5

PwC (PricewaterhouseCoopers) (2018) Auswirkungen der Nutzung von künstlicher Intelligenz in Deutschland. https://www.pwc.de/ de/business-analytics/sizing-the-price-final-juni-2018.pdf.

Rip A, Voß JP (2013) Umbrella terms as mediators in the governance of emerging science and technology. Sci Technol Innov Stud 9(2):40-59. https://doi.org/10.14279/depositonce-4480

Röper H (2016) Zeitungsmarkt 2016: Pressekonzentration erneut leicht gestiegen. Media Perspektiven 5:254-269

Sand M (2019) On "not having a future." Futures 107:98-106. https:// doi.org/10.1016/j.futures.2019.01.002

Saraisky NG (2015) Analyzing public discourse: using media content analysis to understand the policy process. Curr Issues Compar Edu 18(1):26-41

Statista (2017) Made-in-Country-Index. https://de.statista.com/page/ Made-In-Country-Index.

The Federal Government (2018a) Key Points for a Federal Government Strategy on Artificial Intelligence. https://www.bmas.de/ SharedDocs/Downloads/DE/Thema-Arbeitsmarkt/eckpunkte-strat egie-ki.pdf?_blob=publicationFile \&v $=2$

The Federal Government (2018b) Artificial Intelligence Strategy. https ://www.ki-strategie-deutschland.de/home.html?file=files/downl oads/Nationale_KI-Strategie_engl.pdf

Thiel V (2019) Richtlinien für „Ethische KI“: Verbindliche Selbstverpflichtung oder Schönfärberei? Algorithm Watch. https://algor ithmwatch.org/richtlinien-fuer-ethische-ki-verbindliche-selbstverp flichtung-oder-schoenfaerberei/.
Totschnig W (2019) The problem of superintelligence: political, not technological. AI Soc 34:907-920. https://doi.org/10.1007/s0014 6-017-0753-0

UK Government (2018) AI sector deal: policy paper. Department for Business, Energy \& Industrial Strategy and Department for Digital, Culture, Media \& Sport. https://www.gov.uk/government/ publications/artificial-intelligence-sector-deal/ai-sector-deal

United Nations (2019) United Nations activities on artificial Intelligence (AI). https://www.itu.int/dms_pub/itu-s/opb/gen/S-GENUNACT-2019-1-PDF-E.pdf.

Veenman S, Sperling K, Hvelplund F (2019) How future frames materialize and consolidate: the energy transition in Denmark. Futures 114:102473. https://doi.org/10.1016/j.futures.2019.102473

Villani C (2018) For a meaningful artificial intelligence. Towards a French and European strategy. https://www.aiforhumanity.fr/pdfs/ MissionVillani_Report_ENG-VF.pdf

West, S.M., Whittaker, M., Crawford, K. (2019). Discriminating systems: gender, race and power in AI. AI Now Institute. https:// ainowinstitute.org/discriminatingsystems.html.

van Wijck P, Niemeijer E (2016) Scenario planning meets frame analysis: using citizens' frames as test conditions for policy measures. Futures 77:28-44. https://doi.org/10.1016/j.futures.2016.01.005

Williams R (2006) Compressed Foresight and Narrative Bias: Pitfalls in Assessing High Technology Futures. Sci Cult 15(4):327-348. https://doi.org/10.1080/09505430601022668

Wolfe M, Jones BD, Baumgartner FR (2013) A failure to communicate: agenda setting in media and policy studies. Polit Commun 30(2):175-192. https://doi.org/10.1080/10584609.2012.737419

Publisher's Note Springer Nature remains neutral with regard to jurisdictional claims in published maps and institutional affiliations. 